\title{
The Role of the Sports Policy in Promoting Sport for Health in Rwanda
}

Lela Mukaruzima ${ }^{1,2 *}$, Jose M. Frantz ${ }^{1}$

${ }^{1}$ University of the Western Cape, South Africa

${ }^{2} \mathrm{R} w a n d a$ Military Hospital, Kigali, Rwanda

*Corresponding author: Lela Mukaruzima, email: leighla09@gmail.com

\begin{abstract}
Introduction: Physical inactivity is one of the major risk factors of non-communicable diseases that is a threat to public health. While the health benefits of being physically active are well acknowledged, policy strategies to promote health enhancing physical activity are still a challenge especially in Rwanda. This paper aimed to determine how the Rwanda sports policy influences promotion of sport for health.

Methods: A qualitative exploratory case study was used to explore the Rwanda sports policy with particular interest on its responsiveness to promoting sport for health. A desktop policy review was done using two policy process models, followed by semi structured in-depth interviews with 13 key stakeholders of the sports policy.

Results: The Rwanda sport policy as well as its stakeholders acknowledge the health benefits that are linked to sports participation. However, the policy lacks specific goals for promoting sport for health, as it largely focuses on professional sports.

Conclusion: There is a divergence between policy and practice as well as stakeholder's commitment with regard to the Rwanda sports policy in promoting sports for health. Thus, policy makers need to devise a strategic framework with specific objectives that emphasize promotion of physical activity/sports for health.
\end{abstract}

Key words: Sports policy, Physical activity, Health, Rwanda

\section{Introduction}

The World Health Organization (WHO) generally defines policy as a specific official decision or set of decisions designed to carry out a course of action endorsed by a political body which includes goals, priorities and main directions for attaining the desired action.[1] A sports policy, although not entirely a health policy, is indirectly a public health related policy owing to the fact that sports participation has a wide range of health benefits. [2] Sports participation largely contributes to leisure time physical activity (LTPA), which has an important role in improving health.[3]

Unfortunately, despite strong evidence that links regular physical activity participation to good health, physical inactivity is an emerging global health and economic burden and one of the four major predisposing factors of Non-Communicable Diseases (NCDs). [4-6] Furthermore, it is among the neglected high risk behaviors, as compared to the other unhealthy behaviors such as smoking, alcohol and drug abuse.[6,7]

Globally, NCDs are the leading cause of morbidity and mortality having accounted for 63\% of deaths in 2008 . [8] They include; coronary heart disease, most types of cancers, type 2 diabetes and chronic respiratory diseases. They are also known to largely contribute to high mortality rate, increased health expenditures and reduced productivity.[2,6,9,10] Much as NCDs are not the leading cause of mortality in Africa, their prevalence is projected to rise higher than the usual communicable, maternal, perinatal, and nutritional diseases by 2030.[11] In Rwanda, NCDs are on the rise and account for almost more than a quarter of the overall national disease burden. Findings from two different sources, $[12,13]$ show that NCDs account for $25 \%$ and $35 \%$ of the nation burden of diseases in Rwanda respectively.

While some scholars rated physical inactivity as the fourth major predisposing factor of NonCommunicable Diseases (NCDs) globally,[14,15] there are others who suggested that physical inactivity and smoking are the two major predisposing factors of NCDs.[16,17] Globally in 2010, the prevalence of physical inactivity was estimated to be $23 \%$, and on a country level, it was 15\% in Rwanda.[18] However, there 
are other studies that were conducted among different population groups in Rwanda across the last decade that highlight that the majority of Rwandans do not engage in sufficient physical activity especially leisure time physical activity.[19-22] High levels of physical inactivity $(82.6 \%)$ particularly leisure time physical inactivity was reported among people living with HIV/ AIDS.[19] In addition, physical activity levels among people with Diabetes Mellitus, were found to be lowest in the leisure time physical activity category with 223 mean METs/week.[23] Among the elderly, majority (56\%) were insufficiently active,[21] and among Kigali urban women, $72 \%$ of them were physically inactive. [22] In another study conducted among a higher leaning institution, $68 \%$ of the participants who had low levels of physical activity were also associated with diseases like hypertension.[24]

The high levels of physical inactivity among different population groups in Rwanda could be a carry-over from a sedentary younger generation. As highlighted by Dohle \& Wansink,[25] the lack of physical activity in early ages is greatly associated with adult sedentarism. Eleven years ago, the youth who also constitute more than half (67\%) of the Rwandan population were reported to be highly inactive, especially among females (80\%) compared to males (50\%).[26] As much as physical inactivity is an unhealthy risk behaviour, it is also a modifiable risk factor that can be prevented.[27] From this end, the Rwandan government has progressively shown a strong political will to promote physical activity among the general population, as traced through the national sports policy and other legislative strategies. For instance, the prime minister's order that stipulates all civil servants to engage in leisure time physical activity once every week for two paid hours, [28] as well as the recently initiated car free days per month that started in 2016.[29] This initiative started in Kigali city and was extended to the other parts of the country. It aims to reduce the carbon footprint as well as to encourage Rwandans to adopt a healthy lifestyle by engaging in mass sport activities twice every month, while they also receive free medical check-ups from health professionals. [29]

Nonetheless, physical inactivity has not generally gained enough political attention as compared to the other three risk factors: poor diet, alcohol and tobacco consumption.[30] In order to emphasize the importance of promoting physical activity as a means to curtail epidemiologic chronic diseases, research suggests that physical inactivity should be considered as one of the high risk behaviors and thus a need for policies to influence a healthy lifestyle. $[2,30,31]$ In the case of Rwanda where initiatives to promote leisure time physical activity are budding, it is equally important to reinforce sustainability of their implementation for long lasting effects. However, based on the social ecological framework, physical activity participation is a multifactorial behaviour that depends on a number of influences like public policy.[32,33] Hence this paper explored how the Rwanda sports policy promotes sports for health. This was done through a document analysis of the Rwanda sports Policy and in-depth interviews with its stakeholders.

\section{Methods}

\section{Research design}

An exploratory case study design with a specific focus on Rwanda sport policy and its implementing institutions was used. Case studies are in-depth investigations of a single instance of a phenomenon in its real-life context. [34] In this context, data was collected through a desktop analysis of the Rwanda Sports Policy and interviewing its key stakeholders. This paper however reports majorly on the findings of the desktop analysis and which are substantiated by participants' quotes from the interviews. Two policy process models namely ADEPT \& Linear were employed to review the sports policy document. The policy process models have predetermined criteria that were used as checklists to review the policy. Document analysis which is a process of reviewing documents entails careful evaluation and interpretation of data so as to gain a better understanding.[35] The sports policy was carefully and iteratively read with more focus on particular sections that were more pertinent to the research question.[35,36] These included but not were limited to the background, objectives, and implementation strategies. They were thereafter aligned to the relevant determinants of the policy process models in order to identify the different components that are related to promoting sports for health.

The ADEPT (Analysis of Determinants of Policy Impact) model was adopted from Von Wright's theoretical model of human behaviour which is based on four determinants: wants, abilities, duties and opportunities, which were then interpreted as: goals, resources, obligations and opportunities. [37] The Linear model on the other hand follows a rational sequence and has four steps of policy development namely: problem identification, policy formation and adoption, implementation and evaluation.[38,39] Using both models concurrently was an advantage because they have varying strengths and weakness. The researcher 
was able to capture all necessary data without bias as some of the constructs in either model were not easy to assess such as outcome and output in the ADEPT model. Subsequently, semi-structured interviews were conducted with key stakeholders representing the relevant stakeholder institutions. The interviews aimed to explore their opinions and experiences regarding the sports policy and its role in promoting sports for health. The interviews were recorded on an audio tape recorder and field notes were taken when necessary.

\section{Population and sampling}

Qualitative sample size is mainly determined by various factors some of which are data sources from which data are collected in order to address the research objectives. [40] The current study used a purposive sampling to select the sports policy document for analysis as well as its stakeholders to participate in the interviews. [41] For the desktop document analysis, a digital copy of the Sports Policy was accessed from the ministry's website, and a hard copy from the ministry of sports and culture which owns it. This document is the major national policy that guides sport activities in Rwanda hence eligible for analysis. For the interviews, key stakeholders were purposively selected from the relevant institutions. The sample size was made up of a homogenous population drawn from the stakeholder institutions that facilitate implementation of the sports policy as stipulated in the policy.[28] These were specifically representative officials who were in charge of the sports department in those institutions. They included; Ministry of Sports \& Culture, Ministry of health, Ministry of education, Ministry of local government, Ministry of defense, National Rwanda National Police, Rwanda National Olympic Committee, National sports bodies, the Private sector and civil society organizations. Initially, a minimum of eight (8) participants was targeted, one from each organization, where the national Olympic committee was thought to be part of the national sports bodies. However, during the data collection, the researcher saw a need to increase trustworthiness of data, hence a snow ball sampling was further employed to include other relevant participants. In this case, some of the participants who were not sufficiently informed about the policy were asked to recommend their colleagues who had more information. In case of the sports bodies, since they are governed under one structure, their overall chairperson was interviewed, and a representative from one of the registered sports associations in Rwanda. The final sample size which was composed of 13 participants was further determined by saturation of data.[42] Interviews were stopped when we reached a point of informational redundancy, where new information added less or no value to the study.[42]

\section{Ethical considerations}

The study was approved by the Senate Research Ethics Committee of the University of the Western Cape under registration number $14 / 7 / 8$. Also, permission to conduct the study in Rwanda was obtained from the Ministry of Education under reference number; 0308/12.00/2015 and from the National Health Research Committee of Rwanda under reference number: NHRC/2015/ PROT/009. Participants were enlightened about the study and given information sheets containing the aim and objectives of the study before participation. They were requested to sign an interview confidentiality binding form before participation and were informed that their participation is voluntary and that they were free to withdraw from the study at any stage without any consequence. Participants' respect, anonymity and confidentiality were assured.

\section{Data analysis}

Data analysis occurred simultaneously with data collection. [43] Thematic data analysis was employed and the six steps procedure was systematically followed to identify and interpret emerging themes. [36,43] The six steps of thematic analysis involve carefully and iteratively reading of data in order to be well conversant with it. This is followed by the initial coding process, which then leads to generating themes and sub themes. The next step entails revising and refining the identified themes and finally interpreting them into a meaningful text that portrays the reviewed document. $[35,36]$ Thematic analysis was used to identify contents of the sports policy document which correspond to the research questions.[35] This procedure was coupled with the two policy process models that were used to review the sports policy to further guide the analysis. In analysing the interviews, data was transcribed verbatim into text form. The scripts were then coded both manually and using Atlas ti software, following the six step thematic analysis.

\section{Findings}

Results presented in this paper are majorly from the policy review, supplemented by corresponding responses from the interviews with key stakeholders. The policy models were used to deconstruct the policy into sections which made it easier to interpret. Table 1 has a summary of the findings of the sports policy review. 
Table 1. Summary of the rwanda sport policy review

\begin{tabular}{|c|c|c|c|}
\hline \multicolumn{2}{|r|}{ ADEPT Model } & \multicolumn{2}{|r|}{ LINEAR Model } \\
\hline $\begin{array}{l}\text { Determinants of } \\
\text { policy process }\end{array}$ & Policy components & $\begin{array}{l}\text { Determinants of } \\
\text { policy process }\end{array}$ & Policy components \\
\hline 1.Goals & $\begin{array}{l}\text { 1. There are eight goals and none of which is } \\
\text { linked to promoting sports for health. } \\
\text { 2. The goals are related to; } \\
\text { - Administrative management of different } \\
\text { sporting bodies } \\
\text { - Talent identification } \\
\text { - Private sector collaboration } \\
\text { - Capacity building of sports technical officials } \\
\text { - Increase sports publicity to stimulate public } \\
\text { support and participation } \\
\text { - Develop sports facilities that meet } \\
\text { international standards and allow mass } \\
\text { participation } \\
\text { - Promote inclusive sports } \\
\text { - Develop sports in Rwanda for economic } \\
\text { generation }\end{array}$ & 1.Agenda setting & $\begin{array}{l}\text { 1. Improve performance of the } \\
\text { sports federations to make Rwanda } \\
\text { an internationally recognized sporting } \\
\text { nation } \\
\text { 2. Identify talented sports people } \\
\text { who can perform locally and } \\
\text { internationally }\end{array}$ \\
\hline
\end{tabular}

\section{Obligations These included responsibilities and} timeframes. The sports policy has a mandate to promote professional sports and make Rwanda an internationally recognized sporting nation and contribute to the social economic development of Rwanda and its citizens. The policy also states that it has to develop a sporting culture that promotes a healthy lifestyle for Rwandans

\section{Policy 1. A steering committee worked on formulation $\boldsymbol{\&}$ the terms of reference, described Adoption the need for the policy and its implementation strategy \\ 2. Different stakeholders and policy documents consulted to align to nation's priorities}

-Policy adoption 3. A symposium held to finalize the policy formulation -Adoption of policy was based on ten orientations at different levels and their corresponding strategic actions. These include; The ministry of sports and culture, Local Government, National Sports Bodies, Schools, Army and Police institutions, private sector, Media, sports infrastructure development, inclusive sports (Sports for all) and Peace and Development

\section{Resources}

1.Besides the external funding for the policy at 3.Policy Implementation its development stage, the
main financial provider

2. Other strategies to support the policy activities include;

-Private sector, UMUGANDA (community work), - Self-financing business projects

\begin{tabular}{|c|c|}
\hline 4.Opportunities & $\begin{array}{l}\text { 1.The political will } \\
\text { The young population, } 54 \% \text { youth } \\
\text { 2.Political commitment to support sports } \\
\text { development } \\
\text { 3.The geographical setting of Rwanda which is } \\
\text { at a high altitude favors sports training } \\
\text { 4.The developing private sector which may } \\
\text { have to give back to the community } \\
\text { 5.Rwanda as an up and coming country in } \\
\text { terms of business and innovation } \\
\text { 6.Sports may be used as a development tool } \\
\text { to influence the available resources for its } \\
\text { development }\end{array}$ \\
\hline
\end{tabular}

1. Policy orientations and strategic actions further guided implementation mainly based on joint efforts of all stakeholders.
1.Under the ministry of sports and culture, monitoring and evaluation of the policy is to be done through the following activities;

-Quarterly and annual meetings for the stakeholders

-Periodic reviews conducted biannually and annually after 3 years of implementation

-An ongoing database of quantitative and qualitative data consolidated at the national level with input from the various sporting entities

- Periodic surveys (SMS, web surveys, and sample surveys at sporting events) 
Each model has four components which were used as a check list. Each of these components is discussed below and supported by stakeholder's quotations which are presented in italics, with corresponding identity code in brackets. Key stakeholders included directors of sports departments, human resource managers, executive directors and chairpersons of some sports federations. A total of thirteen participants were interviewed, one female and twelve males. They were aged between 34 and 50 years (mean age 41.6 years) and all had at least a university degree in various fields not necessarily related to sports management.

\section{The ADEPT model of policy process}

The main areas of the sport policy that were reviewed using the ADEPT model were mainly the goals, obligations, resources and opportunities. The opportunities are sub-divided into organizational, political and public opportunities. The outcome and output of the policy were not assessed as this was beyond the scope of the study

\section{Goals of the sports policy}

The policy has eight specific objectives which are linked to promoting sports in general and none of them is specifically directed towards promoting health. The objectives were further detailed with an orientation and strategic action plan which describes how each objective will be achieved and at which level. Regarding sport for health, one of the participants pointed out that it was not among the major priorities when developing the policy much as it is acknowledged and indirectly expected:

"...although in our policy it is included that we should promote sports for all, so that all Rwandans should do sports, however, that was not the motivating factor... Of course it's understandable that bealth is part of the policy...” (KI: 8).

\section{Obligations}

Generally, the main obligation identified in the policy was linked to developing professional sports to make Rwanda an internationally recognized sporting nation. Other obligations were specific tasks assigned to each of the stakeholder institutions in alignment to their official designated functions. An example is the ministry of education which was mandated to ensure that physical education is made part of school curriculum. Schools were seen to be ideal settings to promote sport and develop talent from the grassroots. Some stakeholders confirmed that they were selected based on what they do as institutions more than anything else:

"I am not sure if the current sports policy was based on any research, but it gives us some responsibilities as a ministry...... that has many youth... So when they give you a task you can't refuse especially when it is beneficial to the general population" (KI: 7).

\section{Resources}

Only the policy development process was externally funded, other than that, the estimated cost for implementing the policy is expected to be provided by the government, private sector sponsorship as well as through home grown solutions such as the use of "UMUGANDA" (community work) to intervene where necessary. As for human resources, the policy relies mainly on stakeholders' collaboration. A need for adequate financial and human resources to be able to implement the policy was expressed by some stakeholders:

"Basically that's a major challenge we face, the few staff/ employees cannot be able to do the different activities required in implementing the policy of which they don't even have the budget for" (KI: 9).

\section{Opportunities}

The major opportunity for the policy is the strong government's will to support and develop sport in Rwanda as was stated in the policy and also confirmed by some of the participants. "We are lucky that our leaders love sports and so act as role models..." (KI: 4).

Other opportunities include: the Rwandan population which is mainly comprised of the youth (54\%), the geographical setting of Rwanda which is at a high altitude thus favoring sports training.

\section{Linear model}

The linear model of policy process helped to identify the four major steps taken in developing the Rwanda sports policy, i.e., Agenda setting, policy formation and adoption, implementation and evaluation.

\section{Agenda setting/problem identification}

According to the policy, the major problems identified were linked to the underdevelopment of sport in Rwanda generally and not specifically related to health. Thus, the policy was developed in order to advance sports participation in Rwanda. However, this did not concur with some of the key stakeholders' responses. When asked what motivated the development of the sports policy, one key stakeholder pointed out that the policy was developed to update the guidelines for sports in order to have a unified understanding of sports, how 
it should be done as well as its various benefits:

Our main motivator was to put a guiding channel for all stakeholders to have one guiding principle to follow. ...the motivating factor was to put a channel through which people may be told that sport is important to their health but beyond that it can also be a profession. Besides having a healthy life and protection from stress, sport is a good paying profession that sustains those who do it (KI: 8).

\section{Policy formation and adoption}

This stage involved assigning a team of people to define the terms of reference, the need for the policy and its implementation strategy. Various stakeholders were consulted for their opinions and relevant documents reviewed for consistency with other government policy priorities. The Policy was also presented to the cabinet ministers for approval prior to being implemented in 2013: "It was approved on 1"st March 2013..." (KI: 8).

\section{Implementation}

There is an implementation framework developed by the ministry of sports and culture outlining the various tasks of each stakeholder and is mainly dependent on their joint collaboration. Although some of the stakeholders take ownership of the policy, there are others who suggest that the ministry in charge of sports should take a lead in its implementation:

"I suggest the policy owners should come down and work closely with stakeholders, just as we work with sports federations" ...., As a policy, the owners should inform the implementers on the way forward this should be part of their duties (KI: 1).

\section{Evaluation}

Generally, proper evaluation of the policy is still a challenge due to factors like lack of tools, regardless of the well-defined strategies stated in the policy. One of the interviewees indicated so:

"Basically what I can tell you is that we don't have tools to use for monitoring and evaluation (M\&E)..." (P 8).

In order to evaluate the policy objectives, stakeholders are encouraged to set annual performance targets and hold regular meetings to discuss the identified issues. Also, periodic reviews were to be conducted bi-annually and annually after three years of implementation to assess the overall progress and effectiveness. An ongoing database of quantitative and qualitative data consolidated at the national level, as well as periodic surveys (SMS, web surveys, and sample surveys at sporting events) is another procedure intended to measure the policy implementation. However, these were only on paper and not in practice as implied by some stakeholders, for instance:

"...we have never seen people from the ministry of sports come to monitor and evaluate how sports are done. Basically there is no follow up from the ministry" (P1).

\section{Discussion, conclusion and implications for practice}

This paper aimed at investigating the role of the Rwanda Sports Policy towards promoting sports for health. Overall results show that the policy acknowledges the health benefits of sports which are automatically expected when people participate in sports. The sports policy does not directly promote sport for health but rather supports and guides the development of all sports activities in Rwanda generally. The sport activities are divided into three categories: elite sports, mass sports and sports for all. However, development of elite sports seemingly takes precedence over the other categories. For example, there is an aspiration for Rwanda to be ranked among the top ten African countries by 2020 in football and to be among the top three countries in basketball, volleyball, cycling, athletics and Paralympic sports.[28] In addition, one of the stakeholders implied that funding is more readily available to promote elite sports more than other categories

".... they only target the national teams which are sponsored and forget to develop sports at the grass root level...” (KI: 9).

This finding is not peculiar to the Rwanda sports policy alone. Other studies also reported that sports for health is less prioritized in relation to elite sports. [3,44] Eime and colleagues assert that professional sports performance is the influencing factor for the financial support.[3]

Based on the goals or the agenda setting of the sports policy, sports for health does not appear as a priority issue. However, one of the key stakeholders assured that the intention to promote sports for health is implied in the sports policy, even if it is not explicitly stated among the objectives. Whereas this aligns with Bernier and Clavier,[45] who pointed out that policy content includes stated or unstated goals and intentions, there are contradictory findings which emphasize the importance of stated goals in a policy. Sabatier,[46] highlighted that knowledge of the goals and perceptions of various stakeholders of a policy contribute to understanding its process. Similarly, Rutten and colleagues suggested that a combination of solid objectives, sufficient funds and public opportunities such as support from the media and 
population positively impact policies. [47] Therefore, it is crucial for specific goals to be explicitly stated in a policy as this contributes to a positive outcome of the policy. Implementation of the Rwanda sports policy is essentially dependent on key stakeholder institutions which were assigned various tasks in line with what they do regardless of their knowledge about the policy. The downside of this method is that some of the key stakeholders were unclear about their roles in implementing the policy despite it being well stated. Consequently, this reflects a challenge regarding stakeholders' commitment in effectively implementing the policy in its entirety. Literature suggests that for stakeholders to know their various roles, they needed to have sufficient knowledge about the policy in question. $[45,48]$. This concurs with the current findings which linked positive attitudes of stakeholders towards implementation of the policy. Some of the stakeholders who admitted to have participated in the sports policy development were more inclined to implementing it than those who claimed to know little or nothing about it. Although a majority of participants (ten) were aware of the sports policy, only four of them were directly involved in its development, two of whom were from the ministry that owns the policy.

Finally, it is evident that there is a strong political will to promote health enhancing physical activity among Rwandans. This is based on the current progress made in promoting mass sport participation among Kigali city dwellers through the Kigali car free days initiative. [29] Findings of this study also show that the Rwanda sports policy generally acknowledges the health benefits of sports. Nonetheless, the policy lacks specific objectives to promote sports for health. Consequently, this negatively impacts the efforts to support the development and implementation of sports for health. It is therefore noteworthy that more efforts be invested in promoting sport for health as one of the priority needs. The assumption that health benefits are achieved when people engage in sports activities does not translate into participation. Therefore, the lack of specific goals aimed at promoting sports for health on the premise that health is embedded in sports participation poses a challenge of accountability in translating goals into practice. Policy makers or stakeholders may not feel obliged to pursue something that is not a priority. Hence, there is a need to devise a strategic framework with specific objectives aimed at promoting physical activity/sports for health to the wider population. Previous studies stressed the significance of evidence-based policies, whereby evidence influences the decisions of policy makers to develop policies that bring about positive changes.
[49,50] The results of this survey can be used as a reference to address the identified policy gaps such as setting clear goals to achieve policy intentions and the relevance of evaluating policy objectives. Furthermore, the importance of actively engaging all stakeholders in all policy formulation stages should be considered as this enhances their commitment towards implementing it.

\section{Acknowledgements and Funding}

All the stakeholders of the Rwanda sports policy who participated in this study, the Rwanda Education Board for the study loan granted and the National Research Fund of South Africa for the research funds provided.

\section{Conflict of interests}

The authors declare there is no conflict of interest.

\section{References}

1. World Health Organization. World Health Organization: Assessing national capacity for the prevention and control of non-communicable diseases; Report of the 2010 global survey [Internet]. 2012. Available from: http://www.who.int/cancer/ publications

2. World Health Organization. World Health Organization: Steps to Health: A European Framework to Promote Physical Activity for Health. [Internet]. 2007. Available from: http://www. euro.who.int/data/assets/pdffile/0020/101684/ E90191.pdf

3. Eime RM, Harvey JT, Charity MJ, Casey MM, van Uffelen JGZ, Payne WR. The contribution of sport participation to overall health enhancing physical activity levels in Australia: a population-based study. BMC Public Health. 2015;15(1):806.

4. Ding D, Lawson KD, Kolbe-Alexander TL, Finkelstein EA, Katzmarzyk PT, Van Mechelen W, et al. The economic burden of physical inactivity: a global analysis of major non-communicable diseases. Lancet. 2016;388(10051):1311-24.

5. Beaglehole R, Bonita R, Alleyne G, Horton R, Li $\mathrm{L}$, Lincoln $\mathrm{P}$, et al. UN high-level meeting on noncommunicable diseases: addressing four questions. Lancet. 2011;378(9789):449-55.

6. Allender S, Cowburn G, Foster C. Understanding participation in sport and physical activity among children and adults: a review of qualitative studies. Health Educ Res. 2006;21(6):826-35. 
7. Kohl 3rd HW, Craig CL, Lambert EV, Inoue S, Alkandari JR, Leetongin G, et al. The pandemic of physical inactivity: global action for public health. Lancet. 2012;380(9838):294-305.

8. Alwan A, others. Global status report on noncommunicable diseases 2010. World Health Organization; 2011.

9. World Health Organization. World Health Organization: Global Strategy on Diet, Physical Activity and Health. 57th World Health Assembly. [Internet]. 2004. Available from: http://www.who. int/dietphysicalactivity/strategy/

10. Booth FW, Gordon SE, Carlson CJ, Hamilton MT. Waging war on modern chronic diseases: primary prevention through exercise biology. J Appl Physiol. 2000;88:774-87.

11. World Health Organization. World Health Organization: (2011). Global status report on non-communicable diseases 2010 [Internet]. 2011. Available from: .http://apps.who.int/iris/ bitstream/

12. Alleyne G, Binagwaho A, Haines A, Jahan S, Nugent R, Rojhani A, et al. Embedding non-communicable diseases in the post-2015 development agenda. Lancet. 2013;381(9866):566-74.

13. World Health Organization. World Health Organization: (2014). Non-communicable Diseases Country Profiles. 2014.

14. Bonita R, Magnusson R, Bovet P, Zhao D, Malta DC, Geneau R, et al. Country actions to meet UN commitments on non-communicable diseases: a stepwise approach. Lancet. 2013;381(9866):575-84.

15. World Health Organization. World Health Organization: Global Recommendations on Physical Activity for Health [Internet]. 2010. Available from: www.whqlibdoc.who.int/ publications/2010/9789241599979_eng.pdf

16. Wen CP, Wu X. Stressing harms of physical inactivity to promote exercise. Lancet. 2012;380(9838):192-3.

17. Bauman AE, Reis RS, Sallis JF, Wells JC, Loos RJF, Martin BW, et al. Correlates of physical activity: why are some people physically active and others not? Lancet. 2012;380(9838):258-71.

18. World Health Organization. World Health Organization: Global Health Observatory Data. Prevalence of insufficient physical activity. [Internet]. 2015. Available from: http://www.who. int/gho/ncd/risk_factors/physical_activity/en
19. Frantz JM, Murenzi A. The physical activity levels among people living with human immunodeficiency virus/acquired immunodeficiency syndrome receiving high active antiretroviral therapy in Rwanda. SAHARA-J: 2013;10(3-4):113-8.

20. Lela M, Frantz JM. Physical activity among nurses in Kanombe Military Hospital. African J Physiother Rehabil Sci. 2012;4(1-2):63-6.

21. Kanyoni M, Phillips J. Factors associated with physical activity levels among older adults in selected institutions in Rwanda. 2009;

22. Kagwiza JN, Phillips JS, Struthers P. Physical activity profile of urbanized Rwandan women. African J Phys Act Heal Sci. 2005;11(1):59-67.

23. Kabanda AM, Phillips JS. Physical activity among adults with diabetes mellitus in Rwanda: physical activity, health and wellness. African J Phys Heal Educ Recreat Danc. 2011;17(2):239_47.

24. Banyangiriki J, Phillips J. Prevalence of Hypertension among Working Adults in Rwanda. Iran J Public Health. 2013;42(8):925-6.

25. Dohle S, Wansink B. Fit in 50 years: participation in high school sports best predicts one's physical activity after Age 70. BMC Public Health. 2013;13(1):1100.

26. Rwanda Ministry of Youth C\& S. Rwanda Ministry of Youth, Culture \& Sports: National Youth Policy. [nternet]. http://www.youthpolicy.org/national/ Rwanda; 2005. Available from: http://www. youthpolicy.org/national/Rwanda

27. Burden WA, Branch E. The burden of disease and injury attributed to preventable risks to health in Western Australia, 2006. 2010;

28. Republic of Rwanda [RW] M of $\mathrm{S}$ and C [MINISPOC. Sports Development Policy. [Internet]. Rwanda: Webpage; 2012. Available from: http:// www.minispoc.gov.rw/index.php?id $=2$.

29. City of Kigali R of R. Kigali Car Free Days [Internet]. 2016 [cited 2018 Nov 4]. Available from: http:/ / www.kigalicity.gov.rw/index.php?id=16\&tx_ ttnews $\% 5 \mathrm{Btt}$ news $\% 5 \mathrm{D}=67 \& \mathrm{cHash}=$ efbb586f $2 \mathrm{fa}$ afbc8ded68b8f0f9aab06

30. Wen CP, Tsai MK, Wai JPM, Wu X. Promoting increased physical activity and reduced inactivity-Authors' reply. Lancet. 2013;381(9861):114-5.

31. Wen CP, Wai JPM, Tsai MK, Yang YC, Cheng TYD, Lee M-C, et al. Minimum amount of physical activity for reduced mortality and extended life 
expectancy: a prospective cohort study. Lancet. 2011;378(9798):1244-53.

32. Green LW. Health program planning. An Educ Ecol approach. 2005;

33. Stokols D. Translating social ecological theory into guidelines for community health promotion. Am J Heal Promot. 1996;10(4):282-98.

34. Yin RK. Case study research: Design and methods (applied social research methods). London Singapore Sage. 2009;

35. Bowen GA. Document analysis as a qualitative research method. Qual Res J. 2009;9(2):27-40.

36. Braun V, Clarke V. Using thematic analysis in psychology. Qual Res Psychol. 2006;3(2):77-101.

37. Rütten A, Abu-Omar K, Gelius P, Dinan-Young S, Frändin K, Hopman-Rock M, et al. Policy assessment and policy development for physical activity promotion: results of an exploratory intervention study in 15 European Nations. Heal Res policy Syst. 2012;10(1):14.

38. Sutton M, Levinson BA. Policy as practice: Toward a comparative sociocultural analysis of educational policy. Vol. 1. Greenwood Publishing Group; 2001.

39. Porter RW, Hicks I. Knowledge utilization and the process of policy formation: toward a framework for Africa. 1995;

40. Creswell JW. Educational Research: Planning, conducting, and evaluating quantitative and qualitative research. 4th ed. Upper Saddle River, NJ: Pearson/Merrill Education.; 2011.

41. Gentles SJ, Charles C, Ploeg J, McKibbon K. Sampling in qualitative research: Insights from an overview of the methods literature. Qual Rep. 2015;20(11):1772-89.
42. Guest G, Bunce A, Johnson L. How many interviews are enough? An experiment with data saturation and variability. Field methods. 2006;18(1):59-82.

43. Creswell JW. Research Design: Qualitative, Quantitative and Mixed Methods Approaches. SAGE Publications, London EC1Y 1SP, UK; 2014.

44. Keim M, De Coning C. Sport and development policy in Africa: results of a collaborative study of selected country cases. African Sun Media; 2014.

45. Bernier NF, Clavier C. Public health policy research: making the case for a political science approach. Health Promot Int. 2011;26(1):109-16.

46. Sabatier PA. Theories of the Policy Process. In: Paul A. Sabatier, editor. Theories of the Policy Process [Internet]. Westview Press. Colorado; 2007. Available from: http://ruby.fgcu.edu/courses/ twimberley/EVR2861/theorypolprocess.pdf

47. Rütten A, Lüschen $G$, von Lengerke $T$, Abel T, Kannas L, Diaz JAR, et al. Determinants of health policy impact: comparative results of a European policymaker study. Sozial-Und Präventivmedizin. 2003;48(6):379-91.

48. Breton E, De Leeuw E. Theories of the policy process in health promotion research: a review. Health Promot Int. 2010;26(1):82-90.

49. Brownson RC, Chriqui JF, Stamatakis KA. Understanding evidence-based public health policy. Am J Public Health. 2009;99(9):1576-83.

50. Siddiki S. Assessing Policy Design and Interpretation: An Institutions-Based Analysis in the Context of Aquaculture in Florida and Virginia, United States. Rev Policy Res. 2014;31(4):281-303. 